\title{
Roof Tile Powder As a Partial Replacement TO CEMENT IN MASONRY MORTAR
}

\author{
Jiji Antony $^{1}$ and Deepa G Nair ${ }^{2}$ \\ ${ }^{1}$ Department of Civil Engineering, Federal Institute of Science and Technology, \\ Angamaly \\ ${ }^{2}$ Department of Civil Engineering, Cochin University of Science and Technology, Kochi
}

\begin{abstract}
Ordinary Portland cement is an inevitable material for construction. However, it is highly energy intensive and liable for the emission of green house gases. In this context, utilization of pozzolanic materials as supplementary cementing materials has become the leading research interest in recent decades. Roof tile industries generate huge amount of solid waste materials during their manufacturing processes. Disposal of these waste materials is serious environmental concern. This paper presents the results of the study conducted on the potential of roof tile powder (RTP) as a cement replacement material in mortar. The physical, chemical and mineralogical compositions of RTP were investigated. Strength characteristics of masonry mortar with varying proportions of RTP as cement replacement were tested. The test results verify the potential of roof tile powder as partial replacement to cement in masonry mortar upto an extend of 15$20 \%$ in 1:3 and 1:5 mortar proportions respectively.
\end{abstract}

\section{KEYWORDS}

Pozzolanic Materials, Supplementary Cementitious Materials, Compressive Strength.

\section{INTRODUCTION}

Ordinary portland cement (OPC) is an inevitable material for construction. However, it is highly resource intensive and liable for the emission of green house gases. Currently manufacturers find it difficult to locate adequate sources of raw materials due to the excessive exploitation. The raw materials have been produced from the existing natural resources and will have intrinsic damage to the environment due to their continuous exploitation. Affordability of building materials is another major concern of today along with environmental issues. In India, the cost of cement during 1995 was Rs $1.25 / \mathrm{kg}$. while in 2005, the price was increased to three times and in 2015, it is increased to eight times. Moreover, a huge quantity of solid waste is generated annually during construction, mining, municipal, agricultural and commercial activities contributing to the environmental pollution. It is estimated that about 14.5 MT of solid wastes are generated annually from construction industries alone [1]. Potential of solid wastes in building industry as alternative materials is already well established.

Utilization of pozzolanic materials as supplementary cementing materials has become the leading research interest in recent decades. Potential of construction wastes as cement replacement is investigated through this research. Igor et.al [2] established the pozzolanic activity of recycled red ceramic bricks through their research. Strength and durability properties of concrete and mortar using waste brick powder as cement replacement was also established by many researchers $[3,4,5]$. This paper presents the results of the study conducted on the pozzolanic property of roof tile powder (RTP) and its application in masonry mortar. 
Civil Engineering and Urban Planning: An International Journal (CiVEJ) Vol.3, No.2, June 2016

\subsection{Experimental Programme}

The experimental programme consists of three stages such as material characterization, test on pozzolanicity and test on mortar.

\subsection{Material Characterization}

\subsubsection{Cement}

Cement used was 53 grade ordinary portland cement with commercial name Coromandel conforming to IS: 12269:1986.

\subsubsection{Fine aggregate}

River sand was used as fine aggregate and its properties are shown in table 1.

Table 1. Properties of fine aggregate

\begin{tabular}{|l|l|l|}
\hline Sl.no & Properties & Magnitude (RiverSand) \\
\hline 1 & Specific gravity & 2.74 \\
\hline 2 & Bulk density $\left(\mathrm{kg} / \mathrm{cm}^{3}\right)$ & 1.45 \\
\hline 3 & Grading zone & Zone II \\
\hline 4 & Fineness modulus & 3.8 \\
\hline 5 & Bulking & Max bulking at $6 \%$ \\
\hline
\end{tabular}

\subsubsection{Roof Tile Powder}

The waste roof tile pieces were collected from a tile manufacturing unit at Chalakkudy, Trichur district of the state of Kerala, India. The cracked pieces of roof tiles were crushed and sieved through $90 \mu$ IS sieve to obtain standard fineness.

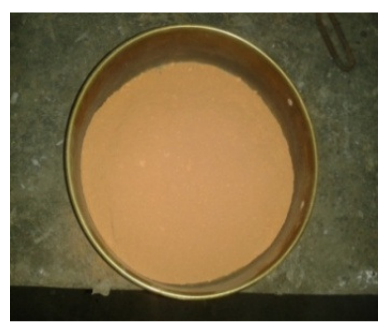

Figure 1. RTP in powder form

\subsubsection{Chemical Analysis of cement and RTP}

A comparison of chemical and physical properties of OPC and RTP are shown in table 2. 
Civil Engineering and Urban Planning: An International Journal (CiVEJ) Vol.3, No.2, June 2016

Table 2. Chemical and physical properties of OPC and RTP

\begin{tabular}{|l|c|c|}
\hline Chemical Analysis & OPC & RTP \\
\hline Loss on ignition & $5.6 \%$ & $2 \%$ \\
\hline $\mathrm{SiO}_{2}$ & $31 \%$ & $62.4 \%$ \\
\hline $\mathrm{Al}_{2} \mathrm{O}_{3}$ & $10.6 \%$ & $8.8 \%$ \\
\hline $\mathrm{Fe}_{2} \mathrm{O}_{3}$ & $4.6 \%$ & $9.2 \%$ \\
\hline $\mathrm{CaO}$ & $42.5 \%$ & $2 \%$ \\
\hline $\mathrm{MgO}$ & $2.2 \%$ & $5.4 \%$ \\
\hline $\mathrm{SO}$ & $2.1 \%$ & $1.7 \%$ \\
\hline Insoluble residue & $23 \%$ & $2 \%$ \\
\hline Specific gravity & 3 & 3.497 \\
\hline Standard consistency & $30 \%$ & $34 \%$ \\
\hline Initial setting time & 115 minutes & 420 minutes \\
\hline Final setting time & 195 minutes & 210 minutes \\
\hline
\end{tabular}

\subsection{Test on pozzolanicity}

The following tests were conducted to establish the potential of RTP as pozzolanic material.

\subsubsection{Specific surface area}

The specific surface area was evaluated using BET (Brunauer, Emmett and Teller) method according to IS 1727-1967.

\subsubsection{Determination of lime reactivity}

Lime reactivity test was conducted as per IS 3812:2003. Cube specimens of size $(70 \mathrm{~mm} \times 70$ $\mathrm{mm} \times 70 \mathrm{~mm}$ ) were prepared and tested. The specimens were cured at 90 to $100 \%$ relative humidiy at $50^{\circ} \mathrm{C}$ and tested. The 28 day compressive strength was found to be $6.3 \mathrm{~N} / \mathrm{mm}^{2}$.

\subsubsection{X- Ray diffraction test}

The diffraction pattern of the materials is important in governing its suitability for use as pozzolanic material in mortar. The X-ray diffraction pattern of RTP was analysed using Joint Committee on Powder Diffraction Standards (JCPDS) database.

\subsubsection{Scanning Electron Microscopy Test}

A scanning electron microscope (SEM) analysis was conducted on RTP to obtain information about the surface topography and composition.

\subsubsection{Electrical conductivity}

The variation of electrical conductivity of a saturated solution of calcium hydroxide on dispersing with the RTP samples can be taken as a measure of the pozzolanic activity of the sample (Luxan et.al 1989). Initially the conductivity of calcium hydroxide saturated solution $\left(200 \mathrm{ml}, 40^{\circ} \mathrm{C}\right)$ is measured. To this $5 \mathrm{~g}$ of RTP sample is added. The electrical conductivity is measured after two minutes of continuous stirring. The difference between the initial and final conductiveness is calculated as a measure of pozzolanic activity. 
Civil Engineering and Urban Planning: An International Journal (CiVEJ) Vol.3, No.2, June 2016

\subsubsection{Soluble fraction of silica}

RTP samples are taken, weighed in an analytical balance and boiled in $100 \mathrm{ml}$ of $2.5 \mathrm{~N}(10 \%)$ $\mathrm{NaOH}$. The solution is then filtered through a filter paper and washed with demineralised water. This filter is dried in an oven at 800 degree Celsius ( 2 hours), cooled and weighed to get the weight of insoluble silica. Soluble silica remained as dissolved in the solution.

\subsection{Tests on Mortar}

Compressive strength and water absorption tests were conducted to establish the strength and durability characteristics of modified mortar.

\subsubsection{Compressive Strength Test}

Mortar cubes were prepared in 1:3 and 1:5 proportions using cement and RTP as binders according to IS 2250:1981. To optimize the replacement of cement with RTP in cement mortar, compressive strength tests were conducted with varying proportions of replacements $(5 \%, 10 \%$, $15 \%$ and $20 \%$ ). Table 3 and 4 shows the results.

Table 3. Compressive strength of modified mortar

\begin{tabular}{|c|c|c|}
\hline \multirow{2}{*}{$\begin{array}{c}\text { Replacement } \\
\text { levels (\%) }\end{array}$} & \multicolumn{2}{|c|}{ Mortar Proportions (1:3) } \\
\cline { 2 - 3 } & $\begin{array}{c}\text { Compressive Strength in } \\
\text { N/mm } \mathbf{m}^{\mathbf{2}} \mathbf{( 2 8} \text { days) }\end{array}$ & $\begin{array}{c}\text { Compressive Strength in } \\
\mathbf{N} / \mathbf{m m}^{\mathbf{2}} \text { (90 days) }\end{array}$ \\
\hline 0 & 22.13 & 26.38 \\
\hline 5 & 19.86 & 23.55 \\
\hline 10 & 16.14 & 17.82 \\
\hline 15 & 12.11 & 14.95 \\
\hline 20 & 5.23 & 9.33 \\
\hline
\end{tabular}

Table 4. Compressive strength of modified mortar

\begin{tabular}{|c|c|c|}
\hline \multirow{2}{*}{$\begin{array}{l}\text { Replacement } \\
\text { levels (\%) }\end{array}$} & \multicolumn{2}{|c|}{ Mortar Proportions (1:5) } \\
\hline & $\begin{array}{c}\text { Compressive Strength in } \\
\left.\mathrm{N} / \mathrm{mm}^{2} \text { ( } 28 \text { days }\right)\end{array}$ & $\begin{array}{c}\text { Compressive Strength in } \\
\mathrm{N} / \mathrm{mm}^{2}(90 \text { days })\end{array}$ \\
\hline 0 & 20.22 & 23.98 \\
\hline 5 & 16.37 & 20.13 \\
\hline 10 & 13.19 & 15.74 \\
\hline 15 & 7.25 & 10.62 \\
\hline 20 & 4.35 & 7.46 \\
\hline
\end{tabular}

\subsubsection{Water Absorption Test}

Water absorption tests of modified mortar specimen of binder: aggregate ratio 1:3 and 1:5 were carried out according to IS 1237 . Table 5 shows the results 
Civil Engineering and Urban Planning: An International Journal (CiVEJ) Vol.3, No.2, June 2016

Table 5. Water absorption at 28 days curing

\begin{tabular}{|c|c|c|c|}
\hline Sl.no & \% Replacement & $\begin{array}{c}\text { \% Water Absorption } \\
(\mathbf{1 : 3})\end{array}$ & $\begin{array}{c}\text { \% Water Absorption } \\
(\mathbf{1 : 5})\end{array}$ \\
\hline 1 & Control Mix & 4.10 & 9.55 \\
\hline 2 & 5 & 4.45 & 9.63 \\
\hline 3 & 10 & 8.81 & 10.24 \\
\hline 4 & 15 & 9.33 & 11.20 \\
\hline 5 & 20 & 12.96 & 15.61 \\
\hline
\end{tabular}

\section{RESULTS AND DISCUSSIONS}

This section presents the discussion of the results of the experimental researches.

\subsection{Chemical Analysis}

The results of chemical analysis of RTP satisfy the requirements of pozzolanic materials with a higher percentage of silica content. The analysis reveals a predominance of $\mathrm{SiO}_{2}, \mathrm{Al}_{2} \mathrm{O}_{3}$ and $\mathrm{Fe}_{2} \mathrm{O}_{3}$ for RTP which satisfies the specifications (min 70\%) of class $\mathrm{N}$ pozzolana as per ASTM C 618.

\subsection{Specific Surface Area}

The specific surface area of the OPC sample was $341 \mathrm{~m}^{2} / \mathrm{kg}$ and that of the RTP was $404 \mathrm{~m}^{2} / \mathrm{kg}$. The higher surface area is an indication of high reactivity and thus improves the pozzolanic property.

\subsection{Lime reactivity}

The lime reactivity test confirms the pozzolanic property of RTP i.e $6.30 \mathrm{~N} / \mathrm{mm}^{2}$ at 28 days where as standard value as per IS 3812 is $4.5 \mathrm{~N} / \mathrm{mm}^{2}$. The higher value is an indication of high pozzolanicity of RTP and micro-filling effect owing to the higher surface area.

\subsection{X- Ray diffraction pattern of roof tile powder}

The diffraction pattern of the materials is important in governing its suitability as a pozzolanic material . The comparison of X-ray diffraction pattern of RTP with reference database is shown in Figure 2.

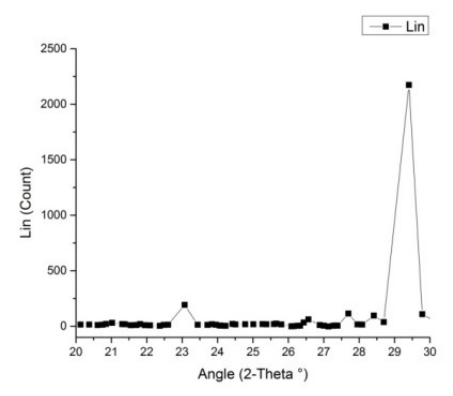

Figure 2. X-Ray diffraction pattern of RTP 
Absence of sharp peak at 2 theta equals to 22 degrees is an indication of the amorphousness of the sample and shows the pozzolanic property of RTP.

\subsection{Scanning electron microscopy}

The result of scanning electron microscopy is shown in figure 3. From the SEM images, it is clear that pore size of RTP is very minute. The surface texture is homogeneous and spherical. Finer particles are traced which confirms the pozzolanic activity of the material.

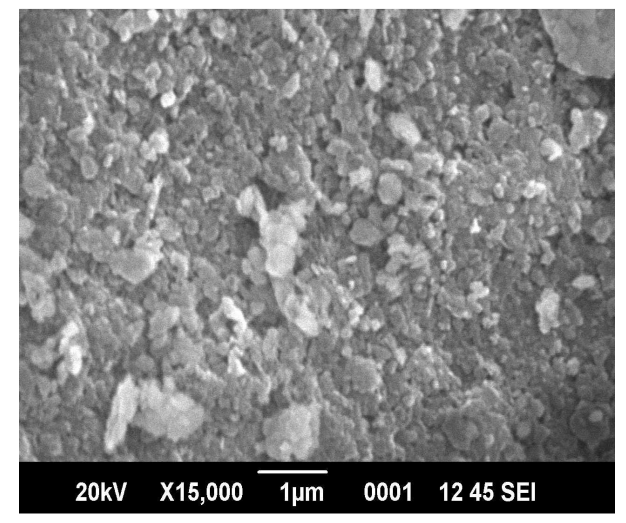

\subsection{Electrical Conductivity}

Figure 3. SEM image of RTP

The results of electrical conductivity showed that RTP samples have large conductivity charges $(1.291 \mathrm{~ms} / \mathrm{cm})$ which can be interpreted as good value for pozzolanic activity. According to Luxan et.al;(1989) variation in electrical conductivity more than 1.2 is referred as good pozzolana.

\subsection{Soluble fraction of Silica}

RTP samples were subjected to chemical analysis for amorphous silica. The results shows highest soluble silica fraction (73.05\%) which is considered as the reactivity of the RTP samples.

\subsection{Compressive Strength}

Figure 4 shows the results of 1:3 and 1:5 combinations of mortar with different replacement levels of cement with RTP varying from $0-20 \%$. A reduction in compressive strength was observed in both the cases as the replacement level increases. The reduction in strength of the mortars may be attributed to the higher water requirement of RTP owing to the higher specific surface area. This results in incomplete reaction during the hydration process and causes a reduction in compressive strength at a water-binder ratio of 0.45 . However, a replacement of cement up to $20 \%$ for $1: 3$ and $15 \%$ for $1: 5$ are possible since the values are above $5 \mathrm{~N} / \mathrm{mm}^{2}$, the minimum specified compressive strength of masonry mortar according to Indian Standards. 

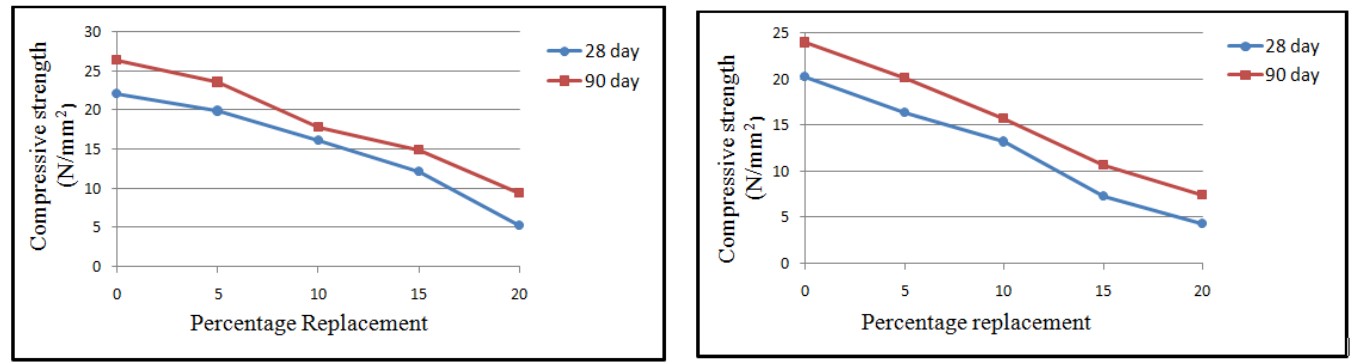

Figure 4. Compressive strength development of 1:3 and 1:5 mortar

\subsection{Water Absorption of Mortars}

Figure 5 represents water absorption of control mix and modified mortar at 28 days of curing age. It was found that water absorption is higher as the amount of RTP increases. This is due to the fact that the roof tile powder has finer particles than those of OPC; consequently, they absorb more water which can be observed from normal consistency data (Table 3). As per IS 1237, the average $\%$ water absorption should not exceed $10 \%$. Hence a replacement of cement up to $15 \%$ for $1: 3$ and $10 \%$ for $1: 5$ is recommended.

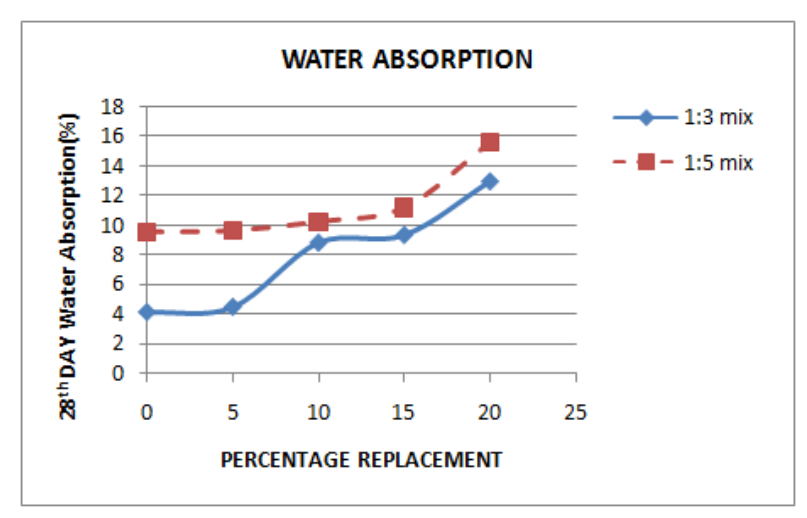

Figure 5. Water absorption of 1:3 and 1:5 mortar at 28 days of curing age.

\section{Conclusions}

In this study, potential of roof tile powder was investigated as a pozzolanic material in masonry mortar. The test results confirm its:-

- Pozzolanic property and categorizes it under class $\mathrm{N}$ pozzolana.

- Potential as partial replacement to cement in masonry mortar to an extent of 10 to15\% for $1: 3$ and 1:5 mortar proportions respectively. 
Civil Engineering and Urban Planning: An International Journal (CiVEJ) Vol.3, No.2, June 2016

\section{REFERENCES}

[1] Asokan Pappu, Mohini Saxena, and Shyam R. Asolekar (2007), "Solid wastes generation in India and their recycling potential in building materials", Building and Environment, Volume 42, Issue 6, , Pages 2311-2320.

[2] Igor S. Pinheiro, Luiz C Montenegro and Adriana G. Gumieri, "Pozzolanic Activity of Recycled Red Ceramic Bricks"

[3] IS 1727-1967, IndianStandard methods of test for pozzolanic materials.

[4] Nuran Ay and Mevlut Unal (2000), "The use of waste ceramic tile in cement product,Cement and Concrete Research, Volume 30, Pp 497-499

[5] Kae-Long Lin, Chyow-San Chiou, Bor-Yann Chen and An Cheng (2009)," Waste brick's potential for use as a pozolan in blended Portland cement", Waste Management and Research, Pp 1-6.

[6] M P Luxan, F Madruga, J Saavedra. Rapid Evaluation of Pozzolanic Activity of Natural Produtcs by Conductivity Measurements. Cement and Concrete Research 1989: 19; 63-68.

[7] ASTM C618: Standard Specification for Coal Fly Ash and Raw or Calcined Natural Pozzolan for Use in Concrete.

[8] IS: 3812-2003, Specification for Fly ash for Use as Pozzolana and Admixture, Bureau of Indian Standards, New Delhi, India.

[9] IS 2250 (1981): Code of Practice for Preparation and Use of Masonry Mortars [CED 13: Building Construction Practices including Painting, Varnishing and Allied Finishing].

[10] IS: 1237 Standard Test Method for Rate of Water Absorption of Masonry Mortars.

\section{Authors}

Jiji Antony was born in 1973 in Ernakulam District of Kerala, India. She received her Bachelor degree of Technology in Civil Engineering from Mar Athanasius College of Engineering, Kothamangalam, Kerala in 1995. In 2005, she received her Master's degree in M.Tech Structural Engineering from Mar Athanasius College of Engineering, Kothamangalam, Kerala. She joined Federal Institute of

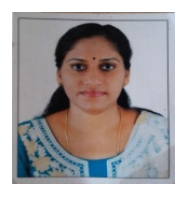

Science and Technology as a Faculty where she is Assistant Professor of Civil Engineering Department with a total teaching experience of 11 years. She has 4 papers published in National conferences and International Journals.

Dr. Deepa.G.Nair is Associate Professor of Civil Engineering, Cochin University of Science and Technology (CUSAT). she acquired her PhD from TU Delft, Netherlands in the year 2006. She has published more than 25 papers in National and International journals and conferences.

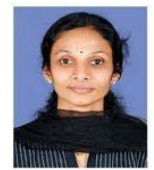

